\title{
Pre-deformation Analysis on Construction of Special-shaped Thin-walled Concrete Acoustic Wind Tunnel Structure
}

\author{
Li Boping ${ }^{1, a}$, Han Dengjiu ${ }^{1}$, Wang Zijian ${ }^{2, b}$ \\ ${ }^{1}$ The 63926 troop of Chinese People's Liberation Army,Beijing China \\ ${ }^{2}$ School of Civil Engineering \& Architecture, Chongqing University of Science \& Technology, Chongqing China \\ abopinglee@126.com, ${ }^{b} 121687678 @ q q . c o m$
}

\begin{abstract}
Structural deformation of special-shaped thin-walled concrete acoustic wind tunnel under self-weight effect can not cater for requirements of high flatness and smoothness of moulding surface. Therefore pre-deformation analysis is carried out on construction of wind tunnel structure. Threshold is utilized to choose equivalent crosssection for the plane needing pre-deformation construction to do analysis. Analysis results show that design specifications of reinforced concrete is feasible for pre-deformation analysis on equivalent plane model under selfweight effect. Present construction on pre-camber wind tunnel according to deflection under self-weight effect also achieves the desired design requirements. Construction technology of arc-shaped erection template which controls mid-span pre-camber value keeps features of simple construction and high accuracy.
\end{abstract}

\section{Introduction}

Low-speed acoustic wind tunnel is a continuous single-reflux one. Size of testing cross section is width $5.5 \mathrm{~m}$ multiplying by height $4 \mathrm{~m}$. Size of tunnel axis is length $142 \mathrm{~m}$ multiplying by width $42 \mathrm{~m}$.

As wind tunnel utilizes frame structure of total ferroconcrete, structure deformation because of its selfweight could not be neglected. Wing tunnel has high requirement on roughness and smoothness of internal surface. Therefore pre-deformation analysis on construction of wind tunnel structure is done aiming at the structure deformation of special-shaped thin-walled wind tunnel under its self-weight effect. Firstly, threshold value of pre-deformation cross section should be taken into account when we do research on permissible thickness of leveling course and surface course required by internal face of wind tunnel to decide the selection of wind tunnel body according to "Wind Tunnel Inwall Terrazzo Surface Construction Method" [1]. Secondly, choose cross section which needs to consider about predeformation threshold value to do plane equivalence and precision verification based on "Code for Design of Concrete Structures" [2]. Finally, propose three kinds of construction pre-deformation project according to deflection under self-weight effect and do ABAQUS [3] comparative analysis on construction convenience and precision of them. Analysis shows that it is feasible to do pre-deformation analysis on equivalent plane model under self-weight effect according to reinforced concrete specification. It caters for prospective design requirements to presuppose construction camber according to deflection under self-weight effect. Construction technology of arced erection template through controlling mid-span pre-arced value has advantages of simple construction and high precision.

\section{Determination of Deformation Threshold and Selection of Pre- deformation Cross Section}

Deformation of wind tunnel under self-weight effect could not cater for roughness requirement of inwall design of wind tunnel. Therefore we utilize predeformation of wind tunnel structure layer namely camber. Reasonably choosing deformation threshold is the key problem for choosing key cross section to do predeformation. Selection of deformation threshold should cater for deformation requirements under gravity effect. Roughness of wind tunnel inwall also needs demonstrating to cater for design requirements. According to research of [1], choose pre-deformation threshold to be $0.5 \mathrm{~cm}$ namely $5 \mathrm{~mm}$.

Establishment of Equivalent Plane Model. Research target of this section is to change complex threedimensional model deformation to be equivalent to simple plane model deformation.

Structural Equivalence Establishment of Plane Model. Choose beam plane frame vertical to wind direction axis to be critical plane. Do equivalence on three-dimensional model in the position of critical plane. Planning

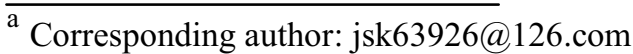


equivalence project is to consider about the function of part of concrete slab according to "Code for Design of Concrete Structures"(GB50010-2010), do equivalence on the original rectangular beam cross section to make it become T-shaped or L-shaped cross section and establish plane structure model.

Load Equivalence of Plane Model. Vertical load of plane model includes uniform load and concentrated load. Uniform load comes from self-weight and slab of beam. Concentrated load comes from sub-beam. Utilizing beam mid-span vertical displacement to be equivalent condition, reasonably select uniform and concentrated loads and suitably correct them on occasion to guarantee that vertical deformation of top structure of plane model basically keeps equivalent to that of three-dimensional model.

Referring to the overall cast-in-place structure of beam slab, simplify slab load to acquire the process during which slab load is passed to sub-beam and then to the main beam.

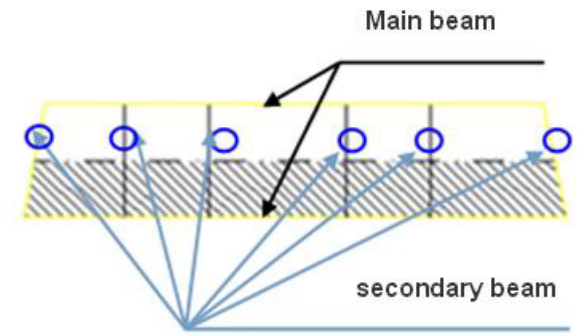

(a) .Equivalent Load on Top of Wind Tunnel

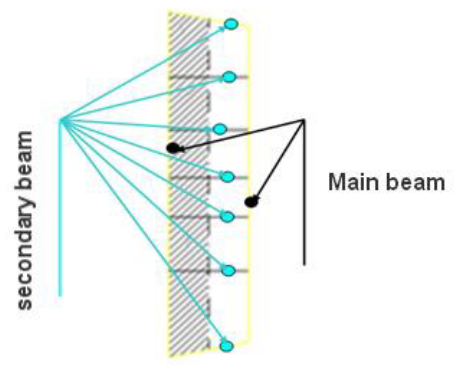

(b). Equivalent Load on Side of Wind Tunnel

Figure 1. Sketches of Load Area Calculation

For top and bottom beams of cross section 1-1, its horizontal ring beam serves as the main beam and vertical beam is the sub-beam. Slab load is passed to 6 sub-beams. About half of the passed load and gravity of sub-beams is passed to beam as shown in dash area of Fig.1(a). For both side, its horizontal beam acts as vertical main beam. Slab load is passed to 7 sub-beams. Then about half of the passed load and gravity of subbeam is passed to side beam of cross section, shown in Fig.1(b).

\section{Checking on Cross Section Utilizing Plane Equivalent Model}

Precision Analysis on Equivalent Plane Model of Critical Cross Section. Determine the critical cross sections 1-1 and 3-3 needing camber based on threshold. Under self-weight effect, deformation appears in mid- span positions on cross section tops of their equivalent plane model and corresponding three-dimensional model. Do comparison on deformation values. Tab. 1 expresses comparative results.

It is seen from Tab.2 that utilizing the above-mentioned plane equivalent model to do pre-deformation analysis could cater for the precision requirements of construction.

Tab.1. Comparison Table of Mid-span Deflection on Critical Cross Section under Self-weight

\begin{tabular}{ccc}
\hline Model & $\begin{array}{c}\text { Mid-span } \\
\text { deflection on 1-1 } \\
\text { Cross Section }\end{array}$ & $\begin{array}{c}\text { Mid-span } \\
\text { deflection on 3- } \\
\text { 3 Cross Section }\end{array}$ \\
\hline 3D model $(\mathrm{cm})$ & 2.06 & 0.98 \\
plane model $(\mathrm{cm})$ & 2.05 & 0.93 \\
Error $(\%)$ & $0.485 \%$ & $5.10 \%$ \\
\hline
\end{tabular}

Pre-deformation Project for Critical Cross Section. Do comparison on different pre-deformation projects with single and multi-control points. In order to lead midpoint of top beam to reach camber requirement and provide convenience for template erection, respectively utilize equal-length two beams with one control point and four beams with three control points on top beam. Through approximate calculation, polygonal beam and arced camber projects are acquired shown in Fig.2.

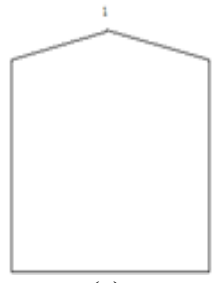

(a)

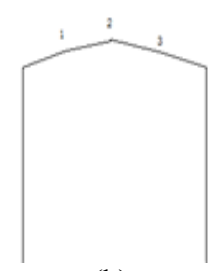

(b)

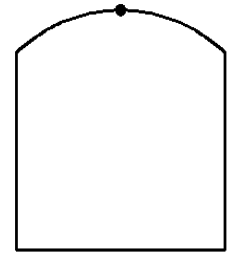

(c)
Figure 2. Erection of Pre-deformation Projects

In these projects, arc of c project in Fig. 3 is determined by reversed deformation of ending point 1 . Its references and concrete steps are seen in Fig.3.

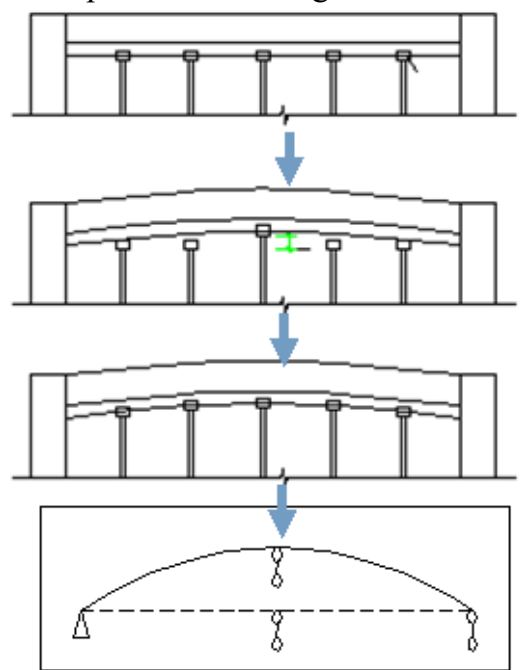

Figure 3. Determination Steps of Arced Camber Arcs

Tab.2 Camber Table of Control Points on 1-1 Cross Section (unit: $\mathrm{cm}$, construction control threshold: $0.5 \mathrm{~cm}$ )

\begin{tabular}{cccc}
\hline $\begin{array}{c}\text { Working } \\
\text { condition }\end{array}$ & $\begin{array}{c}\text { Control } \\
\text { point } 1\end{array}$ & $\begin{array}{c}\text { Control } \\
\text { point2 }\end{array}$ & $\begin{array}{c}\text { Control } \\
\text { point3 }\end{array}$ \\
\hline Project $\mathrm{a}$ & 2.0 & - & - \\
Project $\mathrm{b}$ & 1 & 2 & 1 \\
\hline
\end{tabular}




\begin{tabular}{rlll}
\hline Project c & 2.0 & - & - \\
\hline
\end{tabular}

Tab.3 Camber Table of Control Points on 3-3 Cross Section (unit: $\mathrm{cm}$, construction control precision: $0.5 \mathrm{~cm}$ )

\begin{tabular}{c|c|c|c}
\hline $\begin{array}{c}\text { Working } \\
\text { condition }\end{array}$ & \multicolumn{1}{c}{$\begin{array}{c}\text { Control } \\
\text { point } 1\end{array}$} & \multicolumn{1}{c}{$\begin{array}{c}\text { Control } \\
\text { point } 2\end{array}$} & $\begin{array}{c}\text { Control } \\
\text { point3 }\end{array}$ \\
\hline Project a & 1 & - & - \\
Project b & 0.5 & 1 & 0.5 \\
Project c & 1.0 & - & - \\
\hline
\end{tabular}

The following Tab.2 shows camber values of each control point and control values of mid-span control arcs included in four projects of cross section 1-1 and calculated through quadratic fitting formula. The following Tab.3 shows camber values of each control point and control values of mid-span control arcs included in four projects of cross section 3-3 and calculated through quadratic fitting formula.

\section{Pre-deformation Checking on Critical Cross Section}

\section{Pre-deformation Checking on Equivalent Plane Model of 1-1 Cross Section.}

Tab.4 Residual Deformation Amount in Mid-span Relative Position in section 1-1

\begin{tabular}{|c|c|c|c|c|}
\hline $\begin{array}{l}\text { Project } \\
\text { Deformation }\end{array}$ & Project a & Project $b$ & Project c & Project d \\
\hline Vertical $(\mathrm{cm})$ & -1.945 & -1.857 & -2.016 & -1.922 \\
\hline Mid-span (cm) & 2.0 & 1.5 & 2.0 & 2.0 \\
\hline Residual (cm) & 0.055 & -0.357 & -0.016 & 0.078 \\
\hline
\end{tabular}

It is seen from deformation diagrams of four camber projects of cross section 1-1 that about $2 \mathrm{~cm}$ vertical displacement appears under gravity effect when midspan camber of top beam is $2 \mathrm{~cm}$. The vertical displacement counteracts camber in which beam is straightened to be horizontal. Camber effect is good. Among four kinds of camber projects, effects of a, c and $\mathrm{d}$ projects are good which do not have obvious differences. Considering about erection convenience of construction template, we suggest utilizing a project and $\mathrm{d}$ project which are arced or triangular.

\section{Pre-deformation Checking on Equivalent Plane Model of 3-3 Cross Section.}

Tab.5 Residual Deformation Amount of Mid-span in section 3-3

\begin{tabular}{|c|c|c|c|c|}
\hline $\begin{array}{l}\text { Project } \\
\text { Deformation }\end{array}$ & Project a & Project b & Project c & Project d \\
\hline Vertical $(\mathrm{cm})$ & -0.927 & -0.843 & 0.941 & -0.9236 \\
\hline Mid-span $(\mathrm{cm})$ & 1 & 0.5 & 1 & 1 \\
\hline Residual $(\mathrm{cm})$ & 0.073 & -0.343 & 0.059 & 0.0764 \\
\hline
\end{tabular}

It is seen from deformation diagrams of four camber projects of cross section 3-3 that residual deformation amount is low under gravity effect when mid-span camber of top beam is set to be $1 \mathrm{~cm}$. Application of a, c and d camber projects could reach requirements. This is to say that deformation resulting from gravity effect would counteract camber to keep beam basically horizontal when camber was set to be $1 \mathrm{~cm}$ vertical deformation. Similarly to cross section 1-
1 , we suggest using a project and d project which are arced or triangular for convenient construction.

\section{Conclusion}

Equivalent T-shaped cross section equivalence to the original rectangular beam cross section is an efficient method. Through comparative analysis, it is proved that pre-deformation analysis on plane structure model meets precision requirements.

According to concrete conditions of this project, we do analysis and demonstration to determine that construction pre-deformation threshold should be $0.5 \mathrm{~cm}$. Aiming at the condition of critical cross section surpassing this threshold value which needs predeformation control, camber template erection should utilize project with 1 control point namely arced or triangular project considering about construction.

Research on special-shaped acoustic wind tunnel in this project is done under the premise of simplifying model. Actual measurement and monitoring work is suggested to be done during operation process of wind tunnel in order to do comparative analysis with our research results and further handle structural security and application.

\section{REFERENCES}

[1] Bu Chang-ming. Alien thin-wall concrete structure body piercing and high-precision three- dimensional wind top elevation gradient space construction method research [R].2014.

[2] GB5001 Code for design of concrete structures[S]. 2010.

[3] Shi Yi-ping by, Zhou Yu-Rong.Using ABAQUS finite element analysis of example explan-ation [M].China machine press, 2006 . 